\title{
Possible Creutzfeldt-Jakob Disease (Cjd): Case Report
} \author{
Janaina Silva ${ }^{7}$, Vanessa Dinoá ${ }^{8}$, Pedro Ribeiro ${ }^{9}$ and Marcos RG de Freitas ${ }^{10}$ \\ ${ }^{1}$ Psychiatry student of the Department of Psychiatry and Mental Health, Brazil \\ ${ }^{2}$ Professor of the Department of Psychiatry and Mental Health, Brazil \\ ${ }^{3}$ Master Program in Applied Science in Health, Neurology Service, Brazil \\ ${ }^{4}$ Master Program in Applied Science in Health, Brazil \\ ${ }^{5}$ Neuroinnovation technology \& Brain Mapping Laboratory, Brazil \\ ${ }^{6}$ Department of Physical Therapy - Brain Mapping Laboratory and Functionality, Brazil \\ ${ }^{7}$ Pos-Doutor Student in Brain Mapping Laboratory and Functionality, Brazil \\ ${ }^{8}$ Radiology Department, Brazil \\ ${ }^{9} I P U B$ - Brain Mapping and EEG, Brazil \\ ${ }^{10}$ Neurology Service, Brazil
}

Julia Fernandes Eigenheer ${ }^{1}$, Mauro Vitor Mendlowicz ${ }^{2}$, Marco Orsini ${ }^{3 *}$, Rossano Fiorelli4, Eduardo Trajano ${ }^{4}$ Jonathas Moreira de Sousa ${ }^{4}$, Carlos Eduardo Cardoso ${ }^{4}$, Silmar Teixeira' ${ }^{5}$, Victor Marinho ${ }^{5}$, Vctor Hugo Bastos ${ }^{6}$,

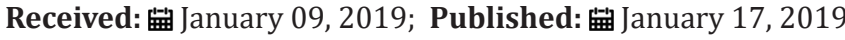

*Corresponding author: Marco Orsini, Rua Professor Miguel Couto, Neurology Service, Bonsucesso, Brazil

Abbreviations: PrPsc: Prion Cell Protein Isoform; sCJD: Sporadic Form; EEG: Electro-Encephalogram; CJD: Creutzfeldt-Jakob Disease; MMSE: Mini Mental State Examination

\section{Introduction}

Prion diseases or transmissible spongiform encephalopathies are rare, incurable and rapidly fatal neurodegenerative diseases [1]. They are associated with the intraneural accumulation of an abnormal Prion cell protein isoform (PrPsc) produced due to a genetic polymorphism, leading to spongiform neuronal degeneration [2]. The term spongiform refers to the characteristic aspect of the infected brain, which starts presenting several cavities, until it appears a sponge microscopically [3]. Creutzfeldt-Jakob disease (CJD) is the most common form of prion disease in humans [1]. The sporadic form (sCJD) presents the highest incidence [4], followed by genetic CJD and sporadic CJD [5], arising without an identifiable genetic or infectious cause, about one person per million inhabitants per year worldwide [2,6]. Although SCDJ is not contagious, it's transmissible to experimental animals and can be transmitted to other humans by iatrogenic mechanisms such as corneal transplants, neurosurgical procedures with contaminated instruments or administration of growth hormone [6].Usually, it manifests itself during the $5^{\text {th }}$ or $6^{\text {th }}$ decade of life, with no difference in incidence between men and women [2], with a typical presentation of rapidly progressive dementia and variable focal involvement of the cerebral cortex, nuclei of the base, cerebellum, brainstem and spinal cord [7]. Changes in behavior (especially in younger patients), aphasia, amnesia, attention deficit, myoclonus and kinetic mutism may be observed in the final stages of the disease. It may eventually present as progressive pseudo-dementia secondary to a depressive syndrome, or more rarely, as a systemic disorder [2]. The present article aims to present a probable case of CJD in a patient with rapidly progressive dementia, based on neurological examination and complementary tests. 


\section{Case Report}

IFC, a previously healthy 54 years-old female retired educator living in Cabo Frio-RJ was seen at a neurology clinic in Niterói, RJ. She was accompanied by family members who reported that the patient had been suffering for six months from a progressively worsening amnestic deficit and had difficulty expressing and dressing herself, as well as unmotivated moments of laughter and crying. During this period, she became less communicative and had less interaction with her relatives. A clinical investigation had already been started elsewhere, with a preliminary diagnosis of dementia not otherwise specified. A neuropsychiatric assessment showed that the patient was lucid, auto psychically oriented, disoriented alopsychically, uncooperative, hypoprosexic, with reduced psychomotricity and facial expression, impaired anterograde and retrograde memories, bradyphalic, hypophonic, paraphasic, with disorganized content. Visual hallucinations were reported during the exam, e.g. an imaginary "boy" was present in the examination room. The MMSE (Mini Mental State Examination) score was low $=6 / 30$. No critical abnormalities were found in the blood counts and biochemistry, including vitamin B12 levels, thyroid function, expression markers, complement, autoantibodies and sorologies for HIV and syphilis. Urine analysis were also normal.

The cerebrospinal fluid features were also within the limits of normality, with negative culture for common germs, Syphilis, Toxoplasmosis, Herpes simplex, Cytomegalovirus and Varicella zoster and protein 14-3-3 absent. Electroneuromyography of the upper and lower limbs showed no abnormalities. A slow, poorly modulated and unstable alpha type electroencephalogram (EEG), with diffuse and bilateral irregular waves of 0.4 to $07.5 \mathrm{~Hz}$, predominant on the frontal areas, with association of frequent diffuse, bilateral and synchronous pseudo periodic three-phase acute activity was found in Figure 1. MRI of the encephalon showed cortical hypersignal in FLAIR with signs of restriction to the diffusion of liquids in the occipital, parietal and frontal lobes (Figure 2).

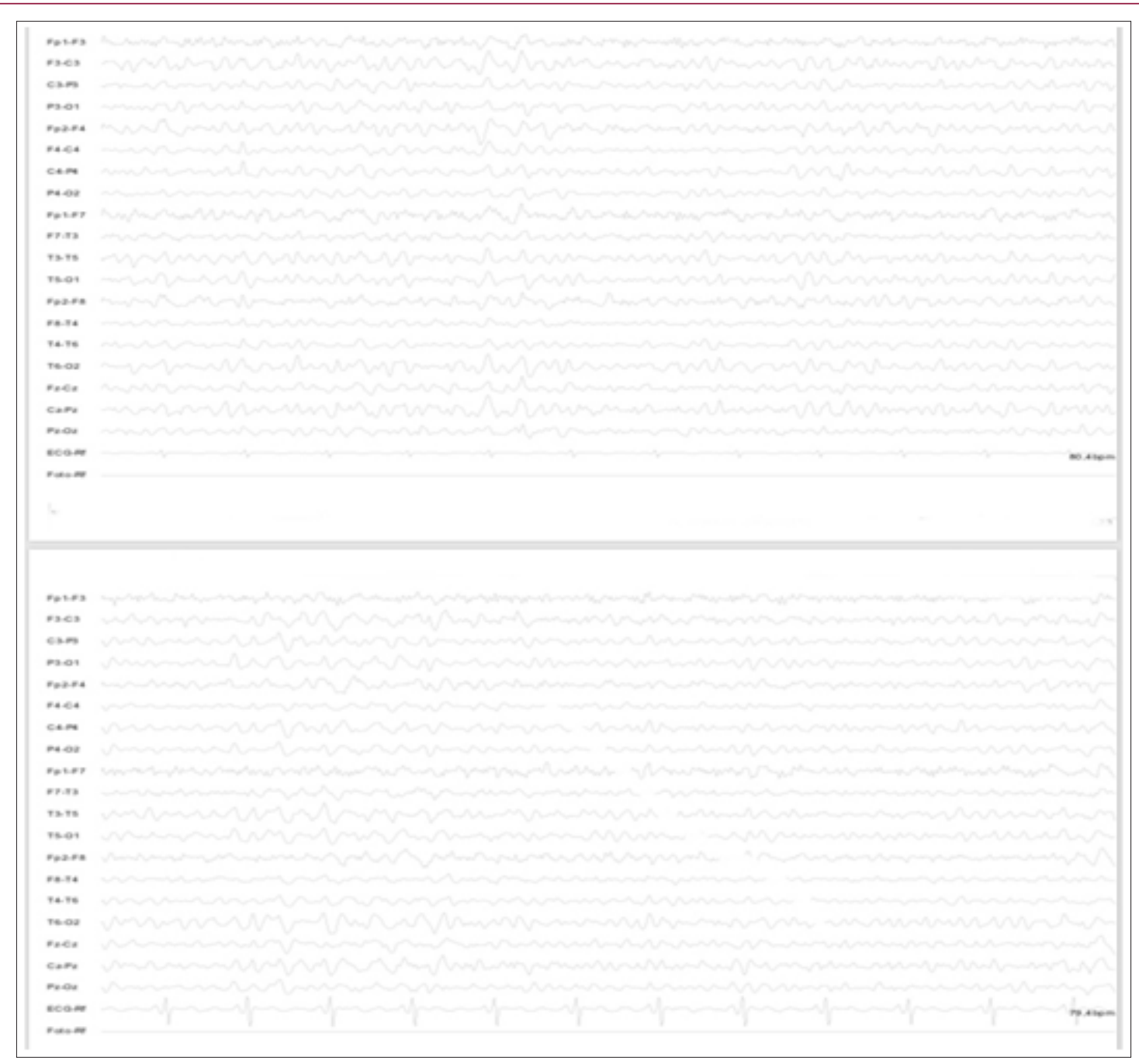

Figure 1: Electroencephalogram. 

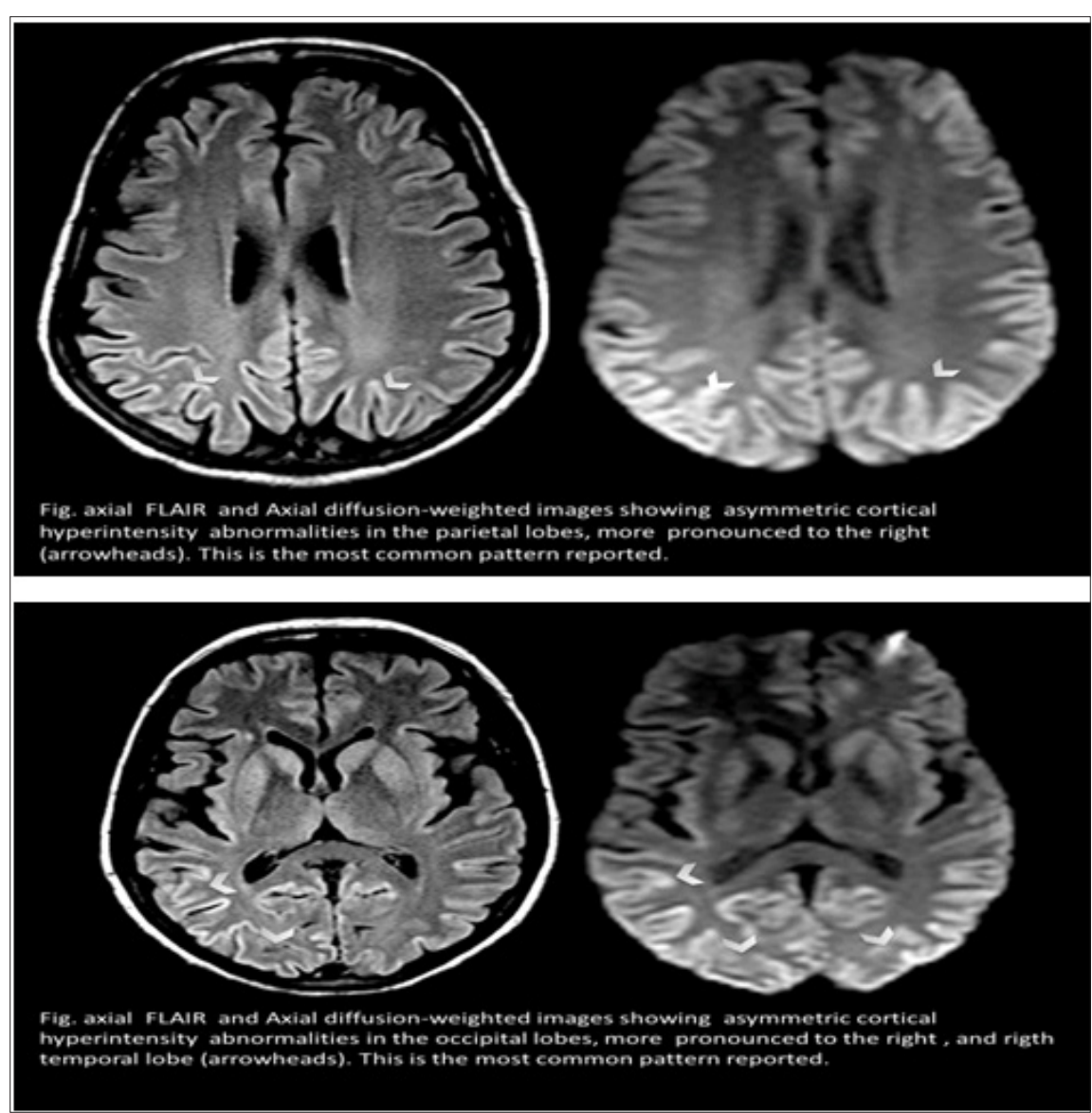

Figure 2: Encephalon MRI.ss

\section{Discussion}

Table 1: CDC's Diagnostic Criteria for Creutzfeldt-Jakob Disease (CJD).

\begin{tabular}{|c|c|c|}
\hline \multicolumn{3}{|c|}{ Sporadic Cjd } \\
\hline Definitive & Probable & Possible \\
\hline $\begin{array}{l}\text { Diagnosed by standard } \\
\text { neuropathological techniques; and/ } \\
\text { or immunocytochemically; and/or } \\
\text { Western blot confirmed protease- } \\
\text { resistant PrP; and /or presence of } \\
\text { scrapie-associated fibrils. }\end{array}$ & $\begin{array}{l}\text { - } \begin{array}{c}\text { Neuropsychiatric disorder plus positive RT- } \\
\text { QuIC in cerebrospinal fluid (CSF) or other tissues }\end{array} \\
\text { OR } \\
\text { - } \quad \text { Rapidly progressive dementia; and at least two } \\
\text { out of the following four clinical features: } \\
\text { - } \quad \text { Myoclonus } \\
\text { - } \quad \text { Visual or cerebellar signs } \\
\text { Anramidal/extrapyramidal signs } \\
\text { AND a positive result on at least one of the following } \\
\text { laboratory tests } \\
\text { a typical EEG (periodic sharp wave complexes) } \\
\text { during an illness of any duration; and/or } \\
\text { a positive 14-3-3 CSF assay in patients with a } \\
\text { disease duration of less than 2 years } \\
\text { Magnetic resonance imaging (MRI) high signal } \\
\text { abnormalities in caudate nucleus and/or putamen on } \\
\text { diffusion-weighted imaging (DWI) or fluid attenuated } \\
\text { inversion recovery (FLAIR) } \\
\text { AND without routine investigations indicating an } \\
\text { alternative diagnosis. }\end{array}$ & $\begin{array}{l}\text { Progressive dementia; and at least two } \\
\text { out of the following four clinical features: } \\
\text { - } \quad \text { Myoclonus } \\
\text { - } \quad \text { Pisual or cerebellar signs } \\
\text { AND the absence of a positive result for any } \\
\text { of the four tests above that would classify a case } \\
\text { as "probable" } \\
\text { AND duration of illness less than two years } \\
\text { AND without routine investigations } \\
\text { indicating an alternative diagnosis. }\end{array}$ \\
\hline
\end{tabular}


The diagnosis of CJD is based on clinical symptoms, EEG findings, magnetic resonance imaging of the skull (MRI), detection of 14-3-3 protein in the cerebrospinal fluid and prion protein gene examination [1] Besides brain biopsy, there is no specific post-mortem test for the diagnosis of CJD [8]. The typical clinical presentation is rapidly progressive dementia, with memory deficit being the most prevalent complaint at the onset of the condition, as in the present case. At an early stage, episodic memory loss and difficulties in acquiring new skills, with gradual impairment in other cognitive functions, such as judgment, calculation, abstract reasoning and visuospatial abilities are characteristic. Later fluent aphasia and apraxia develop, reaching terminal stages with myoclonus, changes in the sleep-wake cycle; behavioral changes; psychotic symptoms; inability to walk and to perform personal care, and akinetic mutism [7,2]. In some cases, it can present as a progressive pseudodementia, secondary to a depressive syndrome or a systemic dysfunction [2]. The Centers for Disease Control and Prevention (CDC) redefined in 2018 the diagnostic criteria for definitive, probable and possible CJD (Table 1) [9]. The patient reported at the first visit, besides the amnestic deficit, clothing apraxia and visual-spatial dysfunction. Later, ataxic ataxia, bradykinesia and fluent aphasia emerged. According to the criteria of the CDC, our patient fits into a probable CJD.

\section{Final Considerations}

One of the major challenges in diagnosis is the wide variety of clinical presentation of the disease. In some cases, the patient does not present dementia, a prerequisite among clinical findings. Even when it is present, it is often mistakenly diagnosed as a dementia of more common types such as vascular, metabolic, infectious and vitamin deficiency. This occurs until typical symptoms such as myoclonus and akinetic mutism arise later and the true diagnosis is finally considered [4].

\section{References}

1. Peckeu L, Delasnerie-Lauprêtre N, Brandel JP, Salomon D, Sazdovitch V, et al. (2017) Accuracy of diagnosis criteria in patients with suspected diagnosis of sporadic Creutzfeldt-Jakob disease and detection of 14-33 protein, France, 1992 to 2009. Eurosurveillance, European Centre for Disease Prevention and Control, 22(41): 21-28.

2. López Serrano A, Bañón Escandell S, Castaño Pérez MD, Safont Gasó P, Esteve Atienzar P, et al. (2016) Two Forms of Presentation of Confirmed Sporadic Creutzfeldt-Jakob Disease. Ann Clin Case Rep 1: 1208.

3. Bello YB, De Almeida ACP, Sueth DM, Belizario EC, Brandao FS, et al. (2014) Probable Creutzfeldt Jakob Disease: case report. American Medical Journal 5(1): 13-15.

4. Rashid AMA, Md Noh MSF, Hoo FK, Sulaiman WAW, Mat LNI, et al. (2017). Creutzfeldt-Jakob Disease (CJD) in Southeast Asia: a diagnostic challenge. Rawal Medical Journal 42(4): 587-589

5. Cramm M, Schmitz M, Karch A, Mitrova E, Kuhn F, et al. (2016) Stability and Reproducibility Underscore Utility of RT-QuIC for Diagnosis of Creutzfeldt-Jakob Disease. Mol Neurobiol 53(3): 1896-1904.

6. Orrú CD, Groveman BR, Hughson AG, Zanusso G, Coulthart MB, et al. (2015) Rapid and sensitive RT-QuIC detection of human CreutzfeldtJakob disease using cerebrospinal fluid. mBio 6(1): e02451-2514.

7. Gallucci Neto J, Tamelini M G, Forlenza OV (2005) Diagnóstico diferencial das demências Rev. Psiq. Clín. 32 (3): 119-130.

8. McGuire LI, Peden AH, Orru CD, Wilham JM, Appleford NE, et al. (2012) Real Time Quaking-Induced Conversion Analysis of Cerebrospinal Fluid in Sporadic Creutzfeldt-Jakob Disease. Annals of Neurology 72(2): 278285.

9. https://www.cdc.gov/prions/cjd/diagnostic-criteria.html

\section{ISSN: 2574-1241}

DOI: $10.26717 / B J S T R .2019 .13 .002373$

Marco Orsini. Biomed J Sci \& Tech Res

(C) This work is licensed under Creative

Submission Link: https://biomedres.us/submit-manuscript.php

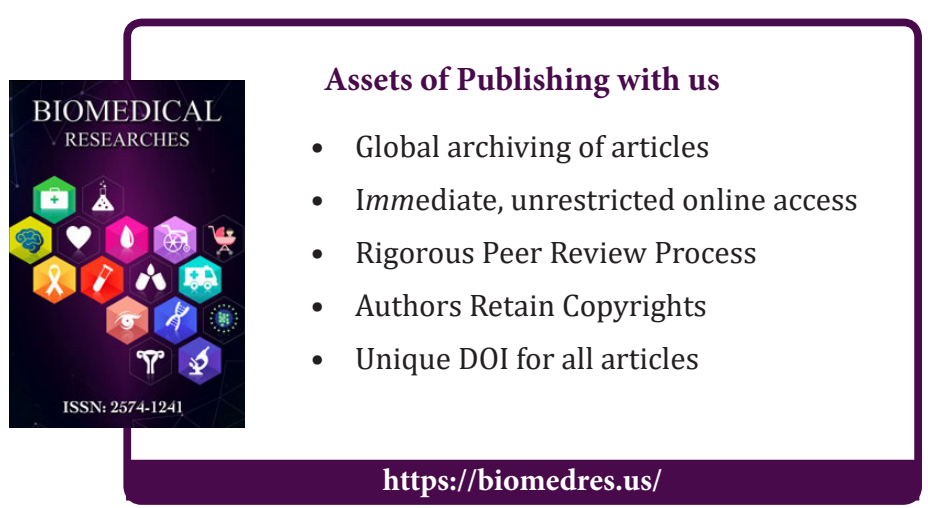

